\title{
Evaluation of preceptors and skills achievement by clinical pharmacy clerkship students during their clinical rotations at University of Gondar, Ethiopia
}

This article was published in the following Dove Press journal:

Advances in Medical Education and Practice

29 March 2016

Number of times this article has been viewed

\author{
Sewunet Admasu Belachew \\ Tadesse Melaku Abegaz \\ Akshaya Srikanth \\ Bhagavathula \\ Henok Getachew \\ Yonas Getaye Tefera \\ Clinical Pharmacy Department, \\ University of Gondar, Gondar, \\ Ethiopia
}

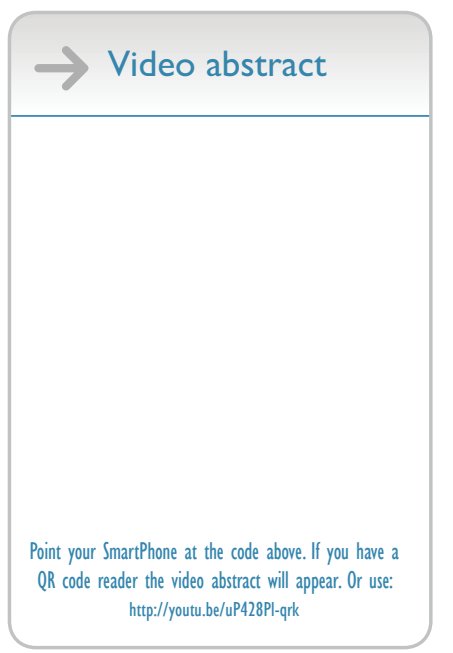

Correspondence: Sewunet Admasu Belachew

Clinical Pharmacy Department, School of Pharmacy, University of Gondar College of Medicine and Health Sciences, Post Box: 196, Gondar, Ethiopia Tel + II 25। 914076544 Fax + II 25I 058 II I479 Email sewunet.admasu@gmail.com
Aim: To investigate the overall experiences of clinical pharmacy students during their clinical attachments and to understand the breadth and depth of clinical skills provided by their preceptors. Methods: A cross-sectional study using a self-administered questionnaire containing 34 items to obtain feedback from the clerkship students from June to July 2015. Data analysis was performed to calculate mean, standard deviation, percentages, and multiple logistic regression using Statistical Package for the Social Sciences (SPSS) software Version 22. Statistical significance was set at $P<0.01$.

Results: All 58 clerkship students actively participated in the study, yielding a response rate of $100 \%$. While students ranked their clerkship experience as moderate, $>15 \%$ remarked that they did not receive enough opportunities to hone their pharmaceutical care documentation skills. A relatively high percentage of students (32.8\%) strongly agreed that their preceptors had provided ample opportunity to discuss the patient problems at the bedside and encouraged them to express their opinions regarding patients' drug therapeutic issues. This study also revealed that students' continuity in developing their therapeutic and disease process knowledge was significantly associated with the preceptor's ability to provide adequate training and orientation ( $P=0.01)$, engagement in clinical pharmacy activities $(P=0.01)$, regular review of students' work $(P=0.01)$, and instruction to students before entering clinical sites $(P=0.00)$.

Conclusion: The findings of this study reveal that a majority of the students were moderately satisfied with the clinical training program and preceptors need to demonstrate effective pharmaceutical care processes in their clinical sites.

Keywords: pharmaceutical care, training, clinical skills

\section{Introduction}

Over the past few decades, the role of a pharmacist was expanded drastically from dispensing medicine to patient care. The paradigm shift of pharmacy profession toward patient care has laid the foundation for pharmaceutical care (PC). ${ }^{1}$ In most of the developing countries, pharmacy organizations and academic training programs adopted PC as the most standard care for patients. ${ }^{2}$ In essence, the PC concept transformed the pharmacy profession toward patient-centered care to maximize the patient-related positive outcomes. However, the pharmacy practice has undergone enormous transformations in recent times. Transition of pharmacy students from the class-based education to hospital-based experiential clerkships provided an opportunity to apply their scientific knowledge into practice. The setting of clerkship trainings was expected to provide effective learning experience to pharmacy students working with other health care professionals under the guidance of expert preceptors. Studies demonstrated 
that the importance of involving pharmacists in the clinical settings results in a safer and more effective medication use of the patients. ${ }^{3,4}$

In Ethiopia, pharmacist providing patient care is still in embryonic stage and the clinical pharmacy profession was very new. In 2008, the health authorities recognized the need of patient-centered pharmacists, and the 4-year undergraduate pharmacy program was upgraded to a 5-year clinical pharmacy program by adding 1-year mandatory clerkship attachments. ${ }^{5}$ Soon after, the National Harmonized Modular Curriculum was framed to empower the undergraduates toward more clinically oriented education. Successively, the University of Gondar-School of Pharmacy (UoG-SP) adopted the National Harmonized Modular Curriculum by initiating hospital-based clerkship training programs for the final-year undergraduates ( 5 th year) in various departments. ${ }^{6}$ In addition to these attachments, students have an opportunity to take elective course focusing on local health issues such as diabetes and HIV/AIDS, along with industrial training program deemed in the curriculum. Despite rigorous instructions, pharmacy students typically begin their clerkship experience with little practical experience of caring for patients.

The clinical clerkship experience is to provide a practical learning experience to apply their knowledge to assess the patients' health issues and provide rational drug treatment, as well as working with professionals who deliver health care. Clinical pharmacy clerkship training is characterized as a 4+1 model, in which pharmacy students spend 4 years in studying various clinical and pharmaceutical subjects in the classroom settings. In the final year, students apply classroom learning to real PC throughout "clerkship attachments" in respective wards and clinics in hospitals. The clinical pharmacy clerkships in UoG-SP are divided into specialty blocks that include internal medicine ( 7 credit hours), ambulatory care ( 7 credit hours), surgery ( 3 credit hours), pediatrics ( 3 credit hours), gynecology and reproductive health (3 credit hours), psychiatry ( 3 credit hours), and emergency medicine ( 3 credit hours). In addition, nonclinical clerkships include community pharmacy (5 credit hours), hospital pharmacy ( 5 credit hours), and drug information service ( 3 credit hours) coupled with 6 months of academic research. ${ }^{7}$

To explicit goals of clerkship experiences and to develop professional skills, preceptors' excellence in nurturing his or her experience, knowledge, and mentoring the students is essential. Students learn professionalism, empathy, and critical thinking about therapeutic problems by observing and following the preceptors in practice settings. ${ }^{8}$ In this regard, preceptor's knowledge, teaching behavior, and role play serve as key factors for student pharmacists. In addition, being a role model focusing on the needs of the students and actively engaging with students is essential to inspire the students and increase their confidence in the clinical environment. However, there is no standard tool yet available to estimate the effectiveness of preceptors' skills in the clinical settings. The only possible way can be obtaining feedback from the students regarding their clerkship experiences in clinical sites and preceptors' teaching skills can provide an evidence to understand the extent of preceptors' involvement in achieving the clerkship goals.

The aim of this study was to analyze the overall experience of clinical pharmacy students during their clinical attachments and to evaluate their preceptors on his or her ability to provide them with the intended experience of clinical skills.

\section{Methods}

A cross-sectional study was conducted using a survey instrument that was administered to obtain feedback from the finalyear clinical pharmacy clerkship students. All the final-year pharmacy students who underwent clerkship training were invited to participate in this study at the end of the academic year in June-July, 2015. The study protocol was approved by the Institutional Review Board of UoG-SP. Verbal informed consent were also obtained from all participants immediately before the administration of the questionnaire, they were also informed that participation was voluntary and that they could withdraw from the study at any stage if they desired.

\section{Study design}

A feedback approach was used to assess the quality of practical skills received by the clinical pharmacy students and further requested to evaluate their primary preceptors on his or her abilities in providing clinical skills during the clerkship attachments.

\section{Assessment tools}

A self-administered survey was adopted from the Kassam's ${ }^{9}$ survey questionnaire conducted on community pharmacy clerkship students in 2006, and necessary modifications were made to suit the local settings. The survey questionnaire was pilot tested on ten randomly selected faculty members to assess its readability and content validity. Refinements were made and better organized before distribution of the final questionnaire to the students. The clerkship students were invited to participate in the survey questionnaire. No financial compensation was provided though complimentary gifts such as pens and hand notes were distributed. 
Overall satisfaction of the clinical pharmacy training program (\%)

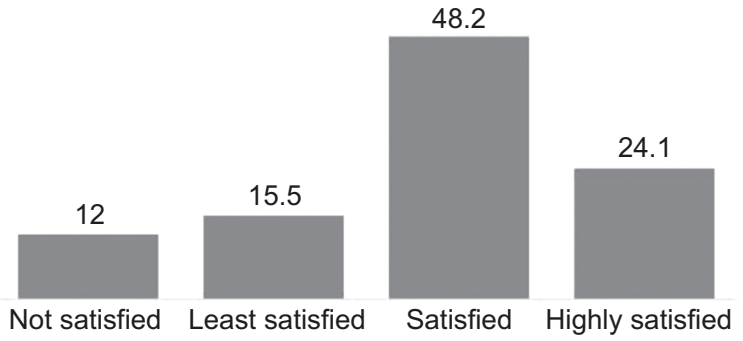

Student opinions on acceptance of clinical pharmacy services in the Gondar University Hospital (\%)

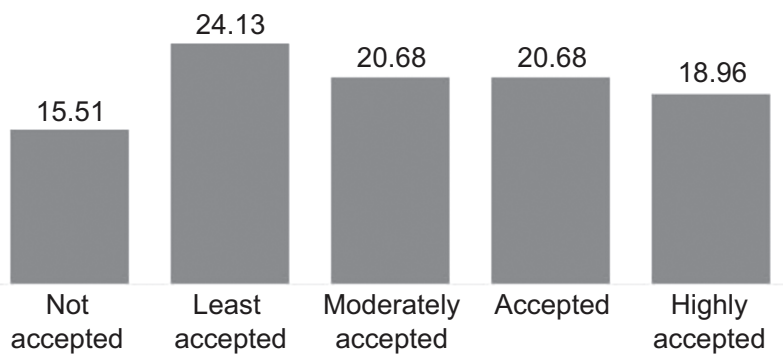

Figure I Clinical pharmacy students' satisfaction of their extent of clinical pharmacy training provided and its acceptance in the Gondar University Hospital ( $=58$ )

\section{Content of the survey questionnaire}

The survey questionnaire comprises five sections with a total of 30 items including:

1. Sociodemographic details (four items),

2. Students overall clinical training program satisfaction (one item, using 4-point Likert scale) and acceptance of their clinical pharmacy services in hospital (one item, 5-point Likert scale),

3. Most identified drug-related problems during their clinical attachments (one item, to select at least one to three options out of ten choices),

4. Students experience at their clinical sites (13 items, 4-point Likert scale ranging from "4-definitely occurred"; "3-partially occurred"; "2-did not occur"; to "1-not applicable"), and

5. Students evaluating their preceptor's abilities to provide their intended experience (ten items, 5-point Likert scale ranging from $1=$ "not applicable"; 2 = "strongly disagree"; to $5=$ "strongly agree") (Figure S1).

\section{Statistical analysis}

The obtained data were entered in SPSS V22.0 (IBM Corporation, Armonk, NY, USA) for analysis. Descriptive statistics and inferential analysis were performed for sociodemographic data. Mean, standard deviation, and percentages were computed for all the other variables. Correlation between student's experiences and preceptor's teaching skills statements was determined using multiple logistic regression. A $P$-value $<0.01$ was considered statistically significant.

\section{Results}

All the 58 clerkship students actively participated and completed the survey (response rate $100 \%$ ), of which the majority of respondents were males (70.7\%) with a mean age of $22.5 \pm 1.31$ years.

When asked about their overall satisfaction toward clinical clerkship training program, $24.1 \%$ of the students expressed that they were "highly satisfied", followed by $48.2 \%$ "satisfied". However, $15.5 \%$ of the students stated that the clinical pharmacy services provided by them were "least accepted" in the Gondar University hospital, whereas a comparable percentage of students reported that their services "fairly accepted" (Figure 1).

\section{Most commonly identified drug-related problems}

During their clerkship in the various wards, the most commonly identified drug-related problems by the students are classified as nonadherence to medications (56.5\%), needs additional drug therapy (50\%), unnecessary drug therapy (48.3\%), and noncompliance to medications (34.5\%). These are summarized in Figure 2.

\section{Students evaluating their clinical sites}

When evaluating their clinical sites (Table 1), between 43\% and $55 \%$ of the students expressed that their site "definitely" provided them with the opportunity to engage in activities that helped them develop their communication skills, interviewing the patients, interprofessional collaboration, therapeutic and disease knowledge, and ward round participation with preceptors. However, $>60 \%$ of the students articulated that activities such as professional maturity and responsibility and problem-solving skills to identify drug-related problems allowed them to interact with patients and other health care providers to improve their clinical skills and level of confidence were "partially occurred". Only small percentage $(15.5 \%)$ of the students expressed that their sites did not 


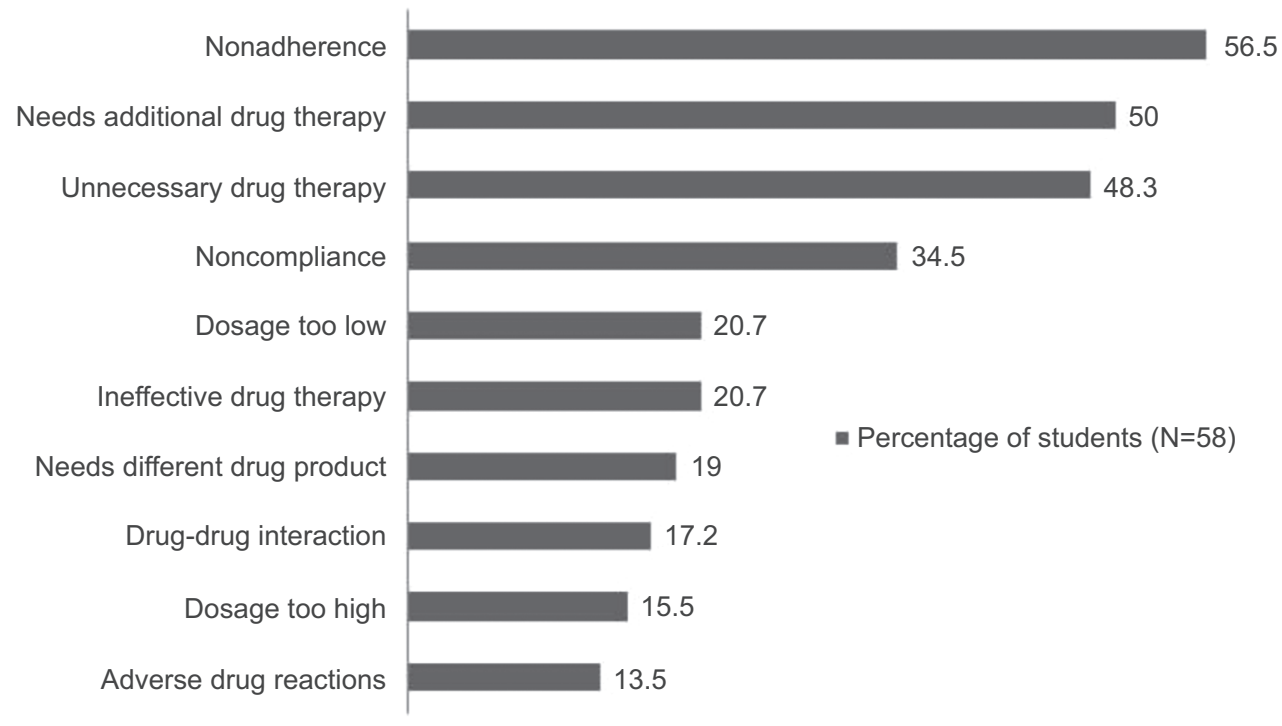

Figure 2 Most identified drug-related problems by the clinical pharmacy students.

Table I Clinical pharmacy students evaluation of the extent to which their clinical sites provide them with the opportunity to provide the following $(\mathrm{N}=58)$

\begin{tabular}{|c|c|c|c|c|c|}
\hline \multirow[t]{2}{*}{ No } & \multirow[t]{2}{*}{ Statement } & \multicolumn{3}{|c|}{ Extent of which these occurred $N=58(\%)$} & \multirow[t]{2}{*}{ Mean \pm SD } \\
\hline & & $\begin{array}{l}\text { Definitely } \\
\text { occurred (2) }\end{array}$ & $\begin{array}{l}\text { Partially } \\
\text { occurred (I) }\end{array}$ & $\begin{array}{l}\text { Not } \\
\text { occurred (0) }\end{array}$ & \\
\hline $\mathrm{Cl}$ & $\begin{array}{l}\text { Develop professional maturity and responsibility in order to } \\
\text { contribute to patient care }\end{array}$ & $18(31.0)$ & $38(65.5)$ & $2(3.4)$ & $1.28 \pm 0.52$ \\
\hline C2 & $\begin{array}{l}\text { Develop their communication skills to establish the pharmacist-patient } \\
\text { therapeutic relationship and understanding of empathy }\end{array}$ & $32(55.2)$ & $26(44.8)$ & - & $1.55 \pm 0.50$ \\
\hline C3 & $\begin{array}{l}\text { Develop their ability to interview patients to obtain relevant } \\
\text { information }\end{array}$ & $28(48.3)$ & $29(50.0)$ & $\mathrm{I}(\mathrm{I} .7)$ & $1.47 \pm 0.53$ \\
\hline C4 & $\begin{array}{l}\text { Developed their problem-solving skills/thought process skills to assess } \\
\text { patient's drug therapy and medical conditions to identify drug-related } \\
\text { problems }\end{array}$ & $17(29.3)$ & $37(63.8)$ & $4(6.9)$ & $1.22 \pm 0.56$ \\
\hline C5 & $\begin{array}{l}\text { Develop their ability to prioritize the drug-related problems } \\
\text { identified in the order they should be addressed }\end{array}$ & $21(36.2)$ & $32(55.2)$ & $5(8.6)$ & $1.28 \pm 0.6 \mathrm{I}$ \\
\hline C6 & $\begin{array}{l}\text { Integrate the theoretical aspects learned in the clinical pharmacy } \\
\text { program for the assessment of drug therapy problems and resolving } \\
\text { the identified problems }\end{array}$ & $20(34.5)$ & $34(58.6)$ & $4(6.9)$ & $1.28 \pm 0.58$ \\
\hline C7 & $\begin{array}{l}\text { Develop their documentation skills using pharmaceutical care plans, } \\
\text { including the drug-related problem, recommendations, monitoring } \\
\text { plan, and follow-up }\end{array}$ & $15(25.9)$ & $34(58.6)$ & $9(15.5)$ & $1.10 \pm 0.58$ \\
\hline C8 & $\begin{array}{l}\text { Continue to develop therapeutic knowledge base and disease } \\
\text { processes }\end{array}$ & $25(43.1)$ & $30(51.7)$ & $2(3.4)$ & $\mathrm{I} .4 \mathrm{I} \pm 0.64$ \\
\hline C9 & $\begin{array}{l}\text { Develop their interprofessional communication and working } \\
\text { relationship skills }\end{array}$ & $27(46.6)$ & $29(50.0)$ & $2(3.4)$ & $1.43 \pm 0.56$ \\
\hline $\mathrm{ClO}$ & $\begin{array}{l}\text { Expand their exposure to patient records and utilization of such } \\
\text { records to provide patient care }\end{array}$ & $22(37.9)$ & $32(55.2)$ & $4(6.9)$ & $1.31 \pm 0.56$ \\
\hline $\mathrm{Cll}$ & $\begin{array}{l}\text { Expand their understanding of the "real" and "perceived" barriers } \\
\text { to providing pharmaceutical care in practice and how these may be } \\
\text { overcome }\end{array}$ & $21(36.2)$ & $32(55.2)$ & $5(8.6)$ & $1.28 \pm 0.59$ \\
\hline $\mathrm{Cl} 2$ & $\begin{array}{l}\text { Give them ample opportunity to interact with patients and health } \\
\text { care providers to improve their clinical skills and increase their } \\
\text { confidence }\end{array}$ & $21(36.2)$ & $35(60.3)$ & $2(3.4)$ & $1.33 \pm 0.61$ \\
\hline $\mathrm{Cl} 3$ & Participate in ward rounds along with preceptors regularly & $25(43.1)$ & $29(50.0)$ & $4(6.9)$ & $1.40 \pm 0.67$ \\
\hline
\end{tabular}

Abbreviation: SD, standard deviation. 
Table 2 Clinical pharmacy student's evaluation of the extent to which their preceptor provided the following $(N=58)$

\begin{tabular}{|c|c|c|c|c|c|c|}
\hline \multirow[t]{2}{*}{ No } & \multirow{2}{*}{$\begin{array}{l}\text { Evaluate your primary preceptor for the } \\
\text { following criteria }\end{array}$} & \multicolumn{5}{|c|}{ Extent to which these occurred (\%) } \\
\hline & & $\begin{array}{l}\text { Strongly } \\
\text { agree }\end{array}$ & $\begin{array}{l}\text { Moderately } \\
\text { agree }\end{array}$ & $\begin{array}{l}\text { Moderately } \\
\text { disagree }\end{array}$ & $\begin{array}{l}\text { Strongly } \\
\text { disagree }\end{array}$ & $\begin{array}{l}\text { Not } \\
\text { applicable }\end{array}$ \\
\hline PI & $\begin{array}{l}\text { Provided adequate orientation including } \\
\text { clinical setting expectations, introduction to staff } \\
\text { in wards and review of student's learning process }\end{array}$ & $12(20.7)$ & $24(4 \mid .4)$ & $14(24.1)$ & $6(10.3)$ & $2(3.4)$ \\
\hline P2 & $\begin{array}{l}\text { Provided the opportunity to engage in all } \\
\text { mandatory activities outlined in the clinical } \\
\text { pharmacy curriculum manual }\end{array}$ & $13(22.4)$ & $28(48.3)$ & $13(22.4)$ & I ( $(.7)$ & $3(5.2)$ \\
\hline P3 & $\begin{array}{l}\text { Met with students regularly to review work } \\
\text { and provide direction and feedback }\end{array}$ & $9(I 5.5)$ & $27(46.6)$ & $14(24.1)$ & $7(\mid 2.1)$ & $\mathrm{I}(\mathrm{I} .7)$ \\
\hline P4 & $\begin{array}{l}\text { Clear instructions were given before } \\
\text { entering to the clinical attachment sites }\end{array}$ & $16(27.6)$ & $22(37.9)$ & $13(22.4)$ & $4(6.9)$ & $3(5.2)$ \\
\hline P5 & $\begin{array}{l}\text { Involved student in active participation } \\
\text { of discussions and problem solving on } \\
\text { the bedside }\end{array}$ & $19(32.8)$ & $25(43.1)$ & II (19.0) & $3(5.2)$ & - \\
\hline P6 & $\begin{array}{l}\text { Was readily available to answer questions } \\
\text { in wards }\end{array}$ & $12(20.7)$ & $25(43.1)$ & $18(3 \mid .0)$ & $3(5.2)$ & - \\
\hline P7 & $\begin{array}{l}\text { Demonstrated pharmaceutical care processes } \\
\text { effectively }\end{array}$ & $8(13.8)$ & $27(46.6)$ & $18(31.0)$ & $3(5.2)$ & $2(3.4)$ \\
\hline P8 & $\begin{array}{l}\text { Encouraged student to use resource } \\
\text { materials and learn on his/her own }\end{array}$ & $12(20.7)$ & $29(50.0)$ & $12(20.7)$ & $2(3.4)$ & $3(5.2)$ \\
\hline P9 & $\begin{array}{l}\text { Encouraged student to express his/her } \\
\text { own opinions in patient's drug therapeutic } \\
\text { issues }\end{array}$ & $19(32.8)$ & $23(39.7)$ & II (19.0) & $4(6.9)$ & $\mathrm{I}(\mathrm{I} .7)$ \\
\hline PIO & Provided patient-centered education effectively & II (I9.0) & $32(55.2)$ & $9(15.5)$ & $2(3.4)$ & $4(6.9)$ \\
\hline
\end{tabular}

provide them with sufficient opportunity to document their interventions for identified drug-related problems.

\section{Students evaluating their preceptors' skills}

When students were asked to evaluate their preceptors on his or her abilities and skills to provide them with the intended experience to horn PC skills (Table 2), 27\%-33\% of the students stated that they "strongly agreed" that their preceptors involved them in discussion and problem solving on the bedside and provided them with an adequate orientation before attending to the clinical sites. However, $50 \%$ of the students "moderately agreed" with the statement that their preceptors encouraged them to use resource materials and to learn by their own and provided them patient-centered education effectively. Additionally, $31 \%$ of the students "moderately disagreed" that the preceptors were not readily available to answer their queries in wards and did not demonstrate PC process effectively. When asked if their preceptors met them regularly to provide direction and review their work to provide feedback, $12.1 \%$ of the students "strongly disagreed".

\section{Associated factors with students' responses for their clinical sites and preceptors' skills}

A significant positive association was observed between each student's experiences of their clinical sites and preceptors' skills evaluation statements. For example, therapeutic and disease knowledge was significantly associated with adequate clinical orientation $(P=0.01)$, engaging them in all of the clerkship's mandatory activities $(0.01)$, preceptors reviewing their work (0.01), provided clear instructions before entering to clinical sites $(0.00)$, modeled PC process effectively (0.01), and encouraged them to use resource materials and to learn on their own (0.00). The results of the associations were summarized in Table 3.

\section{Discussion}

Evaluation by students remains the most common method used to understand the status of preceptors' commitment in clerkship attachments. However, pharmacists providing PC in resource-limited settings can provide them with a unique opportunity to improve the health status of poor patients. The UoG-SP has developed clerkship training program with the goal to improve the PC and health of rural Gondar citizens. Student response has been positive; however, the quality of clinical pharmacy training and motivation is essential to provide quality patient care in the resource-limited settings in Ethiopia. The findings of students' self-rating suggest that student's evaluations of clerkship training and preceptors' skills are valid indicators of clerkship quality. This is the first study to evaluate the clinical pharmacy 
Table 3 Factors associated with students' responses for their clinical sites and preceptor skills

\begin{tabular}{|c|c|c|c|c|c|c|c|c|c|c|c|}
\hline Number & Statements & PI & $\mathbf{P 2}$ & P3 & P4 & P5 & P6 & P7 & P8 & P9 & PIO \\
\hline $\mathrm{Cl}$ & $\begin{array}{l}\text { Developed professional maturity and responsibility in order to } \\
\text { contribute to patient care }\end{array}$ & 0.36 & 0.30 & 0.28 & 0.01 & 0.05 & 0.05 & 0.77 & 0.68 & 0.32 & 0.83 \\
\hline $\mathrm{C} 2$ & $\begin{array}{l}\text { Developed their communication skills to establish the } \\
\text { pharmacist-patient therapeutic relationship and } \\
\text { understanding of empathy }\end{array}$ & 0.44 & 0.77 & 0.97 & 0.37 & 0.73 & 0.45 & 0.80 & 0.17 & 0.66 & 0.66 \\
\hline C3 & $\begin{array}{l}\text { Developed their ability to interview patients to obtain relevant } \\
\text { information }\end{array}$ & 0.00 & 0.30 & 0.10 & 0.09 & 0.55 & 0.29 & 0.74 & 0.31 & 0.17 & 0.90 \\
\hline $\mathrm{C} 4$ & $\begin{array}{l}\text { Developed their problem-solving skills/thought process skills to } \\
\text { assess patient's drug therapy and medical conditions to identify } \\
\text { drug-related problems }\end{array}$ & 0.31 & 0.07 & 0.01 & 0.50 & 0.07 & 0.10 & 0.81 & 0.10 & 0.00 & 0.63 \\
\hline C5 & $\begin{array}{l}\text { Developed their ability to prioritize the drug-related problems } \\
\text { identified in the order they should be addressed }\end{array}$ & 0.47 & 0.00 & 0.00 & 0.05 & 0.06 & 0.05 & 0.34 & 0.22 & 0.00 & 0.22 \\
\hline C6 & $\begin{array}{l}\text { Integrated the theoretical aspects learned in the clinical pharmacy } \\
\text { program for the assessment of drug therapy problems and } \\
\text { resolving the identified problems }\end{array}$ & 0.15 & 0.01 & 0.00 & 0.15 & 0.00 & 0.08 & 0.31 & 0.56 & 0.22 & 0.13 \\
\hline C7 & $\begin{array}{l}\text { Developed their documentation skills using pharmaceutical care } \\
\text { plans, including the drug-related problems, recommendations, } \\
\text { monitoring plan, and follow-up }\end{array}$ & 0.15 & 0.19 & 0.02 & 0.01 & 0.01 & 0.42 & 0.01 & 0.08 & 0.49 & 0.00 \\
\hline C8 & $\begin{array}{l}\text { Continued to develop therapeutic knowledge base and disease } \\
\text { processes }\end{array}$ & 0.01 & 0.01 & 0.01 & 0.00 & 0.02 & 0.40 & 0.01 & 0.00 & 0.08 & 0.12 \\
\hline C9 & $\begin{array}{l}\text { Developed their interprofessional communication and working } \\
\text { relationship skills }\end{array}$ & 0.00 & 0.03 & 0.11 & 0.00 & 0.05 & 0.37 & 0.53 & 0.28 & 0.20 & 0.03 \\
\hline $\mathrm{ClO}$ & $\begin{array}{l}\text { Expanded their exposure to patient records and utilization of such } \\
\text { records to provide patient care }\end{array}$ & 0.49 & 0.09 & 0.96 & 0.20 & 0.72 & 0.92 & 0.44 & $0.5 I$ & 0.36 & 0.72 \\
\hline $\mathrm{CII}$ & $\begin{array}{l}\text { Expanded their understanding of the "real" and "perceived" } \\
\text { barriers to providing pharmaceutical care in practice and how } \\
\text { these may be overcome }\end{array}$ & 0.25 & 0.67 & 0.64 & 0.86 & 0.10 & 0.93 & 0.23 & 0.57 & 0.69 & 0.10 \\
\hline $\mathrm{Cl} 2$ & $\begin{array}{l}\text { Gave them ample opportunity to interact with patients and } \\
\text { health care providers to improve their clinical skills and increase } \\
\text { their confidence }\end{array}$ & 0.19 & 0.16 & 0.18 & 0.09 & 0.00 & 0.57 & 0.05 & 0.02 & 0.32 & 0.04 \\
\hline $\mathrm{Cl} 3$ & Participated in ward rounds along with preceptors regularly & 1.33 & 0.03 & 0.88 & 0.08 & 0.61 & 0.17 & 0.09 & 0.15 & 0.66 & 0.21 \\
\hline
\end{tabular}

clerkship students' experiences and skills provided by their preceptors, and therefore, there are no other studies with which to compare our findings.

The overall results of this 30-item survey used to evaluate the clerkship program showed that students were somewhat satisfied with their training (48.2\%) and preceptors' teaching skills (32.8\%). The student's survey suggested that more than half of the students believed they definitely received opportunity to develop their communication skills to establish patient-pharmacist relationship. Effective communication is essential to improve the medications used by patients and to ensure optimal therapeutic outcomes. ${ }^{10}$ In addition, pharmacists' communication skills can improve drug therapy adherence through tailoring appropriate strategies by counseling and educating the patients. ${ }^{11}$ Further, practicing these skills is an important component to develop interpersonal skills during clinical rotation experiences. However, when asked to evaluate if their preceptors involved them adequately in all the mandatory activities, nearly half (48.3\%) moderately agreed to strongly agreed (22.4\%). These findings suggest the need of preceptors' excellence in motivating and effective mentoring to provide a meaningful experience for students.

In spite of numerous efforts to provide PC, documenting their interventions for the identified drug-related problems is an essential part of clerkship program. In our study, nonadherence $(57 \%)$ and need of additional drug therapy (50\%) were most commonly identified by the clerkship students, whereas a previous study conducted on similar institution identified unnecessary drug therapy (43\%) and nonadherence (33\%) as the major drug-related problems. ${ }^{7}$ However, only one-fourth of the students indicated that activities related to hone PCrelated documentation skills were "defiantly" occurred than 
others. It appears that some of the students had difficulty in understanding the importance of documenting experiences to hone PC skills. In quality assessment of the advanced pharmacy practice course in the USA, students' need to document the number and type of pharmacotherapy recommendations during their clinical experiences is essential to assure the pharmacy students' activities. ${ }^{12}$ Although this was an important activity noted in the clerkship manual of UoG-SP, completing the tasks during practical experiences will make the students learn the impact of pharmaceutical interventions made during clinical attachments. These interventions are essential to document as a proof to promote clinical pharmacists providing patient care.

When students were asked how well their preceptors had provided their clinical skills, more than half of them "agreed" that their preceptors had provided patient-centered education effectively. Preceptors providing quality patient-centered education can foster the students' ability to think independently and develop effective problem-solving skills. During patient-centered education, students will pay attention to preceptor's demonstrations about a wide variety of patient health issues that will help the students to develop their competency in many areas. To fulfill these needs, preceptors must spend a lot of time and effort on fulfilling the learner's needs. This will provide a unique learning opportunity to the students during their rotations. In the study of Young et al, ${ }^{8}$ a significant number of students (64.5\%) felt that their preceptors served as role models in changing their attitude and practice $(P<0.001)$. It is an essential component to be a role model so as to motivate the students and reflect their preceptors' interest in teaching on bedside. However, nearly half of the students (46.6\%) moderately agreed that their preceptors' involved them effectively in demonstrating the PC process and met them regularly to review their work. These results were comparatively lower than Kassam's ${ }^{9}$ study, where $>60 \%$ of the community pharmacy students strongly agreed with these statements. This highlights the need of preceptor's interaction with the students and devoting some time to understand whether the students meet their needs. This exercise helps to establish a strong student-preceptor relationship and to review their progress.

This research has provided a unique opportunity to understand the students' experiences and evaluating the preceptors' commitment and enthusiasm during clinical attachments. Further, timely evaluation of preceptors and feedback from the students regarding their clerkship training can provide opportunity to identify the barriers and improve the quality of clinical pharmacy clerkship training program. This approach is innovative and provides important information for further research, education, and practice.

\section{Limitations}

The study was conducted in a single institution and cannot be generalized to other institutions in Ethiopia. Further, data presented here are self-reported, and some of the students may provide extreme responses than others, due to the motivations and beliefs, which might lead to recall bias.

\section{Conclusion}

The results provided a valuable insight to understand the perspectives of students toward their preceptor skills. This investigation revealed that nearly half of the clerkship students $(48.2 \%)$ were satisfied with the clinical pharmacy training program and more than half of them opinioned that their clinical sites provided them an opportunity to hone PC skills. Further, most of the participants moderately agreed that their preceptors had provided patient-centered education effectively. However, emphasis should be given to preceptors training as a crucial component in providing effective mentorship for the clinical pharmacy clerkship students during their clinical rotations in Ethiopia.

\section{Disclosure}

The authors report no conflicts of interest in this work.

\section{References}

1. Hepler CD, Strand LM. Opportunities and responsibilities in pharmaceutical care. Am J Hosp Pharm. 1990;47(3):533-543.

2. Bhagavathula AS, Sarkar BR, Patel I. Clinical pharmacy practice in developing countries: focus on India and Pakistan. Arch Pharma Pract. 2014;5(2):91-94.

3. Stemer G, Laml-Wallner G, Kuegler I, et al. Comprehensive evaluation of clinical pharmacists' interventions in a large Australian tertiary care hospital. Eur J Hosp Pharm. 2012;19(6):529-534.

4. Kheir N, Awaisu A, Sharfi A, Kida M, Adam A. Drug-related problems identified by pharmacists conducting medication use reviews at a primary health center in Qatar. Int J Clin Pharm. 2014;36(4):702-709.

5. Odegard PS, Tadeg H, Downing D, et al. Strengthening pharmaceutical care education in Ethiopia through instructional collaboration. Am J Pharm Educ. 2011;75(7):134.

6. Mekonnen AB, Yesuf EA, Odegard PS, Wega SS. Implementing ward based clinical pharmacy services in an Ethiopian University Hospital. Pharm Pract (Granada). 2013;11(1):51-57.

7. Tsega B, Bhagavathula AS, Sarkar BR, Melaku T, Shewamene Z. Impact of clerkship attachments on students' attitude toward pharmaceutical care in Ethiopia. Adv Med Educ Pract. 2015;6:385-391.

8. Young S, Vos SS, Cantrell M, Shaw R. Factors associated with students' perception of preceptor excellence. Am J Pharm Educ. 2014;78(3):53. 
9. Kassam R. Students' and preceptor' experiences and perceptions of a newly developed community pharmacy pharmaceutical care clerkship. Pharm Educ. 2006;6(3):179-188.

10. Mesquita AR, Lyra DP, Brito GO, Balisa-Rocha BJ, Aguiar PM, de Almeida Neto AC. Developing communication skills in pharmacy: a systematic review of the use of simulated patient methods. Patient Educ Couns. 2010;78(2):143-148.
11. Beardsley RS, Kimberlin CL, Tindall WN. Communication Skills in Pharmacy Practice: A Practical Guide for Students and Practitioners. Philadelphia, PA, USA: Lippincott Williams \& Wilkins; 2012.

12. Lundquist LM, Moye PM. Resident physicians' acceptance of pharmacy students pharmacotherapy recommendations during an ambulatory care advanced pharmacy practice experience. Am J Pharm Educ. 2009;73(8):145. 


\section{Supplementary material}

Dear Participants,

The clinical attachment for the clinical pharmacy students is designed for providing opportunities to learn the clinical skills and necessary competencies to permit providing pharmaceutical care via involvement with direct patient care. During the clinical attachment the students are expected to assess the patient for identifying and resolving drug-related problems, educating and providing individualized pharmacotherapy plan.

As a part of the curriculum preceptors are expected to demonstrate the adequate clinical skills which are necessary for providing pharmaceutical care at clinical sites. Therefore, ongoing quality assurance is needed to ascertain how preceptors are providing opportunities and engaging in demonstrating comprehensive clinical skills. The objective of this study is to analyze the overall experience of the clinical pharmacy students during their clinical attachment and to evaluate their preceptors on his or her ability to provide them with the intended clinical skills and deemed experiences. The collected information will be anonymously recorded and only used for research purposes.

\section{Are you willing to participate 1. Yes}

\section{2. i) Socio-demographic features:}

- Sex:

- Age (Years):

- Marital Status:

- Primary preceptor qualification: Other (specify).
Male___ Female

$18-21 / 22-25 / 26-29 />30$

Unmarried/married/divorced/widowed

$\mathrm{MSc} / \mathrm{Pharm} \mathrm{D} / \mathrm{PhD}$

\section{ii) Students evaluation toward their preceptors and clinical settings}

- How do you rate your overall clinical training program: Rate 1/2/3/4/:

- How do you rate your hospital environments toward accepting clinical pharmacy services: Rate 1-5:

iii) The most identified drug-related problems (clinical intervention types) during clinical attachments $(\sqrt{ }$ mark from any 1-3)

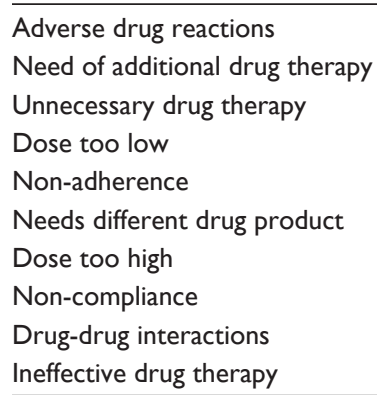

iv) Students evaluation for the extent to which their clinical sites provided them with the opportunities are as follows

\begin{tabular}{|c|c|c|c|c|c|}
\hline \multirow[t]{2}{*}{ SN } & \multirow[t]{2}{*}{ Students evaluation for their clinical sites } & \multicolumn{4}{|c|}{ Extent to which these occurred } \\
\hline & & Definitely & Partially & No & Not applicable \\
\hline I. & $\begin{array}{l}\text { Developed professional maturity and responsibility in order to } \\
\text { contribute to patient care. }\end{array}$ & & & & \\
\hline 2. & $\begin{array}{l}\text { Developed their communication skills to establish the pharmacist-patient } \\
\text { therapeutic relationship and understanding of empathy. }\end{array}$ & & & & \\
\hline 3. & $\begin{array}{l}\text { Developed their ability to interview patients to obtain relevant } \\
\text { information. }\end{array}$ & & & & \\
\hline 4. & $\begin{array}{l}\text { Developed their problem solving skills/thought process skills to } \\
\text { assess patient's drug therapy and medical conditions, to identify } \\
\text { drug-related problems. }\end{array}$ & & & & \\
\hline 5. & $\begin{array}{l}\text { Developed their ability to prioritize the drug-related problems identified in } \\
\text { the order they should be addressed. }\end{array}$ & & & & \\
\hline
\end{tabular}


6. Integrated the theoretical aspects learned in the PharmD program for the assessment of drug therapy problems and resolving the identified problems.

7. Developed their documentation skills using pharmaceutical care plans, including the drug-related problem, recommendations, monitoring plan and follow-up.

8. Continue to develop therapeutic knowledge base and disease processes.

9. Developed their inter-professional communication and working relationship skills.

10. Expanded their exposure to patient records and utilization of such a record to provide patient care.

II. Expanded their understanding of the "real" and "perceived" barriers to provide pharmaceutical care in practice, and how these may be overcome.

12. Given them ample opportunity to interact with patients and health care providers to improve their clinical skills and increase their confidence.

13. Participated in ward rounds along with preceptors regularly.

v) Students evaluation for the extent to which their preceptor fulfilled the expectations are as follows

SN Evaluate your primary preceptor for the following criteria

\begin{tabular}{lllll} 
Extent to did these occurred & & \\
\hline Strongly & Moderately & $\begin{array}{l}\text { Moderately } \\
\text { disagree }\end{array}$ & $\begin{array}{l}\text { Strongly } \\
\text { disagree }\end{array}$ & $\begin{array}{l}\text { Not } \\
\text { applicable }\end{array}$ \\
Agree & agree & lisal
\end{tabular}

I. Provided adequate orientation including clinical setting expectations, introduction to staff in wards, and review of student's learning process.

2. Provided the opportunity to engage in all the mandatory activities outlined in the PharmD curriculum.

3. Met with students regularly to review work, provide direction and feedback.

4. Clear instructions were given before entering to the clinical attachment sites.

5. Involved student in active participation of discussions and problem solving at the bedside.

6. Preceptor was readily available to answer questions in wards.

7. Demonstrated pharmaceutical care processes effectively.

8. Encouraged students to use resource materials and learn on their own.

9. Encouraged students to express their own opinions in patient drug-therapeutic issues.

10. Provided patient-centered education effectively.

Figure SI. Experiences and perception of clinical pharmacy clerkship students toward clinical skills provided by their preceptors during clinical attachments at the University of Gondar, Ethiopia.

\section{Publish your work in this journal}

Advances in Medical Education and Practice is an international, peerreviewed, open access journal that aims to present and publish research on Medical Education covering medical, dental, nursing and allied health care professional education. The journal covers undergraduate education, postgraduate training and continuing medical education including emerging trends and innovative models linking education, research, and health care services. The manuscript management system is completely online and includes a very quick and fair peer-review system. Visit http://www.dovepress.com/testimonials.php to read real quotes from published authors. 